\title{
Neuroliderazgo como estrategia para el fortalecimiento de la gestión directiva en instituciones educativas
}

Neuro-leadership as a strategy for the strengthening of management in educational institutions

\section{Volumen 20, Número 1 \\ Enero - Abril \\ pp. 1-29}

\section{Eduardo Alfonzo Atencio Bravo \\ Luz Jazmín Ramírez Lora \\ Yuly Beatriz Zappa Berastegui}

\section{Citar este documento según modelo APA}

Atencio Bravo, Eduardo Alfonzo; Ramírez Lora, Luz Jazmín y Zappa Berastegui, Yuly Beatriz. (2020). Neuroliderazgo como estrategia para el fortalecimiento de la gestión directiva en instituciones educativas. Revista Actualidades Investigativas en Educación, 20(1), 1-29. Doi. 10.15517/aie.v20i1.40160 


\title{
Neuroliderazgo como estrategia para el fortalecimiento de la gestión directiva en instituciones educativas
}

\author{
Neuro-leadership as a strategy for the strengthening of management \\ in educational institutions \\ Eduardo Alfonzo Atencio Bravo ${ }^{1}$ \\ Luz Jazmín Ramírez Lora ${ }^{2}$ \\ Yuly Beatriz Zappa Berastegui ${ }^{3}$
}

\begin{abstract}
Resumen: Comprender la gestión directiva en instituciones educativas a la luz de la neurociencia, ha dado origen al abordaje de las potencialidades del cerebro a favor del ejercicio del liderazgo como estrategia emergente, por lo cual, este estudio censal, se centró en proponer estrategias basadas en neuroliderazgo para el fortalecimiento de dicha gestión en la Institución Educativa Pueblo Bujo del municipio de Montería, Córdoba-Colombia en el año 2017-2018. Metodológicamente, el artículo se enmarcó en el paradigma empírico analítico de enfoque cuantitativo, mediante un tipo de investigación proyectiva con diseño de campo - no experimental. La población estuvo constituida por 40 sujetos pertenecientes al personal directivo y docente de la institución en cuestión, a quienes se les suministró bajo consentimiento informado, un cuestionario bajo la escala de Likert con 33 ítems, cuya confiabilidad se cálculo con la fórmula Alfa de Crombach, arrojando 0,83. Los hallazgos del estudio argumentan que las áreas de enfoque del neuroliderazgo, el estilo de liderazgo asumido, y las habilidades directivas desempeñadas son aceptables; sin embargo, se precisa con debilidad la gestión y el liderazgo emocional ejercido por el personal directivo de la institución, lo que evidencia la necesidad de formular estrategias con énfasis en la neuroplasticidad, neuroaprendizaje y capacidad atencional de los involucrados. Las conclusiones refieren una urgida reformulación del ejercicio estratégico directivo, donde el factor emocional afectivo debe ser reforzado frente al cognitivo - racional, asimetría que manifiesta disparidad en cuanto al uso de recursos que posibilitan la eficiencia, efectividad y eficacia de los procesos.
\end{abstract}

Palabras clave: neuroliderazgo, estrategias de fortalecimiento, gestión directiva.

Abstract: Understanding management in educational institutions in the light of neurosciences, has given rise to the approach of the potential of the brain in favor of the exercise of leadership as an emerging strategy, therefore, this census study, focused on proposing strategies based on neurolide Leadership for the strengthening of said management in the Pueblo Bujo Educational Institution of the municipality of Montería, Córdoba-Colombia in 2017-2018. Methodologically, the article was framed in the empirical analytical paradigm of quantitative approach, through a type of projective research with field design - not experimental. The population consisted of 40 subjects belonging to the management and teaching staff of the institution in question, who were provided with informed consent, a questionnaire under the Likert scale with 33 items, whose reliability was calculated with the Crombach's Alpha formula, throwing 0.83. The study findings argue that the areas of focus of neurolide Leadership, the style of leadership assumed, and the managerial skills performed are acceptable; however, the management and emotional leadership exercised by the institution's management personnel are clearly needed, which demonstrates the need to formulate strategies with an emphasis on neuroplasticity, neuro-learning and the attentional capacity of those involved. The conclusions refer to an urgent reformulation of the strategic management exercise, where the emotional - affective factor must be reinforced against the cognitive - rational, asymmetry that shows disparity in the use of resources that enable the efficiency, effectiveness and effectiveness of the processes.

Key words: neuro-leadership, strengthening strategies, management.

\footnotetext{
${ }^{1}$ Universidad Metropolitana de Educación, Ciencia y Tecnología. Vicerrector Académico, Docente del Doctorado en Ciencias de la Educación, Panamá. Dirección electrónica: eduaten88@hotmail.com ORCID https://orcid.org/0000-0003-0294-5289

2 Institución Educativa Pueblo Bujo, Panamá. Docente de aula. Magister en Administración y Planificación Educativa, Universidad Metropolitana de Educación, Ciencia y Tecnología, Panamá. Dirección electrónica: Jaz197505@gmail.com ORCID https://orcid.org/0000-0003-0966-3663
}

3 Institución Educativa Pueblo Bujo, Panamá. Docente de aula. Magister en Administración y Planificación Educativa. Panamá, Universidad Metropolitana de Educación, Ciencia y Tecnología. Dirección electrónica: Espyuly.zappa203024@gmail.com ORCID https://orcid.org/0000-0002-3486-9172

Artículo recibido: 18 de junioi, 2019

Enviado a corrección: 8 de octubre, 2019

Aprobado: 18 de noviembre. 2019 


\section{Introducción}

El término liderazgo de acuerdo con la Organización de las Naciones Unidas para la Educación, la Ciencia y la Cultura (Rojas y Gaspar, 2006, p. 18) no tiene una raíz latina, como la mayoría de los vocablos del español, su origen es de la lengua inglesa y se deriva del vocablo "lead", el verbo "to lead" que se refiere a la capacidad de conducir hombres". En ese sentido, el abordaje de las habilidades de liderazgo para el desarrollo y auge de las organizaciones educativas es un fenómeno en constante construcción y ha sido producto de diversos estudios realizados en áreas del conocimiento como la Neurociencia, la cual es considerada según Gómez (2004, p. 6), como "la ciencia que estudia las relaciones mentecerebro y los procesos mentales desde un abordaje interdisciplinario".

Es por ello, que el liderazgo como habilidad y/o competencia emergente del gerente educativo, se ha considerado en esta última década como un factor determinante que argumenta la experimentación de factores tanto internos como externos, los cuales condicionan la forma de actuar del rector de una institución educativa, conforme a sus modelos mentales, pensamiento sistémico, entre otras dimensiones, que representan su praxis ante la consecución de logros y metas organizacionales. De allí que los últimos adelantos y aportaciones científicas, enfatizan las bondades del cerebro y la canalización de sus recursos a fin de fortalecer la relación afectiva y sociocognitiva entre los miembros de la comunidad escolar.

Braidot (2013, p. 56), destaca innumerables resultados que el campo de la Neurociencias ha logrado en los últimos años, donde el cerebro, mente y espíritu no son compartimentos estancados. En otras palabras, el autor referido, señala que alguien que sufra un daño en los lóbulos frontales puede cambiar su personalidad, y pasar de ser social a antisocial, de equilibrado a agresivo o de optimista a depresivo; si dicha lesión se produce en la parte anterior o lateral, puede perder, la noción de las consecuencias que su conducta provoca en quienes lo rodean.

Es posible presumir entonces que existen en el cerebro elementos específicos que pudiesen ejercer singularidad en los seres humanos, de igual modo que existen factores internos (personales y actitudinales) o externos (ambientales o contextuales) que podrían llegar a incidir en el rendimiento del cerebro, y consecuentemente, es posible diferenciar comportamientos y capacidades en las personas que son producto de los múltiples estímulos a los cuales se expone el ser humano. 
En ese orden de ideas, múltiples investigaciones develan la vinculación del liderazgo con los recursos neuronales del cerebro dispuestos desde el campo de la neurociencias, aspecto que denota una gran relevancia desde los argumentos de Caballero y Lis (2016), quienes en la universidad Central de Colombia, se refirieron al liderazgo desde una aproximación neurocientifica, lo que adicionado a los hallazgos obtenidos por Mena (2016), justifica la razón de ser del neuroliderazgo como clave para la generación de la neuroplasticidad autodirigida en la gerencia, partiendo de las potencialidades del cerebro humano.

Goleman y Boyatzis (2008, p.2-3), refieren que los grandes líderes son aquéllos cuya conducta apalanca poderosamente el sistema de interconexión del cerebro...donde el liderazgo eficaz trata de tener circuitos sociales poderosos en el cerebro denominándose como inteligencia social, la cual se define como un conjunto de competencias interpersonales construidas sobre circuitos neuronales específicos (y sistemas endocrinos relacionados) que inspiran a los otros a ser eficaces.

Lo establecido por los autores anteriores deja explicita la idea de que las habilidades de liderazgo son distintivas y que además pueden obedecer a unas características que pueden ser desarrolladas o fortalecidas en contextos determinados. Por consiguiente, desde el ámbito educativo es preciso analizar en detalle los procesos de Neuroliderazgo que pueden incidir en el progreso de la calidad y desempeño de las instituciones educativas.

Resulta posible entonces plantear la necesidad de una gestión directiva con alto sentido de pertenencia, que reconozca y valore la autonomía y el liderazgo como aspectos necesarios para una transformación social, en la cual la escuela pueda posicionarse como un agente de cambio para los jóvenes y su futuro; no obstante, para lograrlo será necesario contar con un capital humano representado por rectores líderes que realmente pongan de manifiesto sus potencialidades emocionales, cognitivas, y motivacionales, ante la gestión educativa que demanda empatía, comunicación, entre otras variantes que habrían de garantizar el logro de los objetivos establecidos desde el ejercicio de sus potenciales neurálgicos, aspecto que día a día recobra un gran interés e intervención en pro del logro de una gestión directiva efectiva desde la perspectiva centrada en las habilidades blandas.

El estudio del neuroliderazgo en este caso, se centra en la desarticulación existente entre los procesos cognitivos y emocionales que pueden estimular el potencial requerido por el personal referido para el cumplimiento de su gestión directiva, la cual es su mayor responsabilidad, debido a que implica la "manera cómo el establecimiento educativo es 
orientado. Dicha gestión se centra en el direccionamiento estratégico, la cultura institucional, el clima y el gobierno escolar, además de las relaciones con el entorno" (MEN, 2008, p.27). Todas estas funciones del rector deben ir encaminadas hacia el logro de metas comunes de poblaciones educativas que están esperanzadas en la escuela como medio para mejorar su calidad de vida.

Complementariamente, vale la pena destacar que el personal directivo de la Institución objeto de estudio, demanda además un probable liderazgo compartido por medio del cual sea posible la construcción de escenarios de participación, capaz de trabajar colectivamente y activamente en todos los aspectos de la gestión para lograr satisfacer las necesidades educativas de los y las estudiantes, y cumplir adecuadamente con los propósitos nacionales, lo que significa que tanto rectores como coordinadores deben reinventarse continuamente mediante la formulación e implementación de estrategias cónsonas con la neuroemoción, neuroaprendizaje y neuroplasticidad.

En atención a todo lo antes expuesto el objetivo medular de este artículo se centra en proponer estrategias basadas en neuroliderazgo como estrategia para el fortalecimiento de la gestión directiva en la Institución Educativa Pueblo Bujo del municipio de Montería, Córdoba-Colombia, atendiendo las areas de enfoques que este propone, el estilo de liderazgo y las habilidades directivas desempeñadas por los rectores en cuestión, con el fin de dar respuesta a la siguiente interrogante de estudio: ¿Cuáles estrategias basadas en neuroliderazgo son oportunas para fortalecer la gestión directiva en la Institución referida con anterioridad?. En líneas generales, es imperante destacar que este artículo emerge como producto del trabajo especial de grado efectuado en el contexto de la Maestría en Administración y Planificación Educativa de la Universidad Metropolitana de Educación, Ciencia y Tecnología de Panamá, durante el periodo 2017 -2018, el cual se abordó sin financiamiento alguno por parte de empresas privadas u organismos gubernamentales afines al campo de estudio.

\section{Referente teórico}

\subsection{Neuroliderazgo como estrategia de gestión directiva}

En el contexto gerencial postmoderno, el estudio del neuroliderazgo ha brindado importantes orientaciones al hecho educativo, gracias a las distintas aproximaciones científicas que se han realizado para explicar y comprender los procesos de liderazgo, aprendizaje, adaptabilidad y variación en las acciones humanas. En vista de ello, resulta 
relevante destacar que la relación entre neurociencia y educación es un vínculo fundamental que permite contribuir al mejoramiento de la labor educativa.

Para Braidot (2013, p. 2), quien ha logrado establecer con importante cientificidad las características de una ciencia moderna, refiere que el neuroliderazgo intenta definir la base neuronal del liderazgo y de la gestión, estudiando los procedimientos del cerebro que explican la conducta reflejada en el desempeño del individuo, la motivación, la toma de decisiones, la inteligencia emocional, la forma de relacionarse con otros, la inteligencia y aprendizaje individual, entre otros aspectos vinculados al mundo organizacional y del ejercicio del liderazgo propiamente.

Por consiguiente, el aporte de Braidot, representa una focalización de las acciones de un líder, particularizando su desempeño, es decir, se reconoce las capacidades distintas o acciones que llevan a diferenciar a un líder de otros individuos, logrando además definir ciertas características como las ya mencionadas, entre las cuales se destacan: la disposición para trabajar en equipo, la facilidad para resolver situaciones, la motivación, entre otras; aspectos que precisamente son los que desde el neuroliderazgo hacen posible establecer en función de un rol o desempeño la dirección de una empresa o en este caso institución educativa.

En ese sentido, es posible precisar que el neuroliderazgo corresponde a un conocimiento oportuno que ha logrado consolidarse en un contexto que demanda mayor información acerca del cerebro y las funciones que este desempeña en el desarrollo del ser humano, y por ende, en las economías y las organizaciones en el mundo. No obstante, es importante mencionar que diversas instituciones insertas en la sociedad del conocimiento, han establecido sus paramentos alrededor de aspectos como objetivos, metas, propósitos, recursos materiales y humanos, requiriendo aun de herramientas concretas que permitan definir las características del personal idóneo para dirigir y desempeñar con éxito la responsabilidad de dirigir una organización.

Consecuentemente, el neuroliderazgo se ha considerado como una disciplina de saber propio fundamental para la comprensión del cerebro de los líderes en la época postmoderna, para lo cual autores como Arana plantean una serie de elementos, acciones, emociones o habilidades que son recurrentes en las personas con capacidades para el liderazgo, para ello el autor considera que el neuroliderazgo logra establecer unas áreas de enfoque o de estudio a través de los cuales es posible comprender las acciones, capacidades y emociones que caracterizan a un líder. En otras palabras, el autor refiere que el neuroliderazgo se 
enfoca en los conocimientos y emociones que se articulan para la toma de decisiones, que incluye las habilidades para solucionar conflictos, la dirección de grupos de trabajo, el autoaprendizaje y el aprendizaje gerencial, lo que respecta a procesos creativos y motivacionales. (Arana, 2012, p.5).

Lo anteriormente expuesto pone en evidencia las distintas funciones a las que se encuentra sujeto el cerebro de un líder, lo cual permite establecer que corresponde a ciertos procesos que lo hacen original y singular, puesto que desarrollar con éxito todos los procesos y responsabilidades que de él emanan solo corresponderían aquellos líderes que demuestren las actitudes y capacidades anteriormente descritas.

A ello se suma lo planteado por Dispenza (2007, p. 2), quien sostiene que otra de las funcionalidades del cerebro es la neuroplasticidad, la cual consiste en "la capacidad del cerebro de reformarse, remodelarse y reorganizarse". Como la habilidad del cerebro de modificar o alterar su propia estructura como consecuencia de la experiencia y del pensamiento, para adaptarse a los cambios que el entorno impone o para funcionar de otro modo.

En relación con lo planteado se asume en este estudio el cerebro como un órgano dinámico por medio del cual el sujeto puede lograr ajustar y modificar sus procesos tanto de aprendizaje como de adaptación, en la medida que de manera exitosa logre resolver las eventualidades que día a día se le presentan ante su gestión como director, destacando de igual modo que las capacidades de un líder deben evidenciarse en la media en la que no solo logra desarrollar con éxito sus necesidades y proyectos, sino que logra hacer que las personas la organización educativa también lo alcance.

Se tiene entonces que la gestión directiva representa el escenario idóneo para poner en marcha todas aquellas aptitudes y actitudes a través de las cuales un líder se proyecta hacia una meta. En ese sentido, se hace necesario potenciar los diversos elementos que se articulan y son fundamentales para el logro de la gestión directiva, como lo son el horizonte institucional, el currículo y la cultura o sociedad en la cual se encuentra inmersa la escuela. Adicionalmente, vale destacar que de manera específica la gestión directiva en el contexto educativo también cumple con unos principios que son abordados por Blejmar (2005) quien logra establecer lo siguiente:

Gestionar es hacer que las cosas sucedan, la gestión, más que hacer en forma directa, crea condiciones para el mejor hacer del colectivo institucional, esa responsabilidad recae en el rector quien debe generar situaciones para que cada uno de los integrantes 
de la comunidad den su mejor esfuerzo a la causa común, para que no solo sean planes sino acciones y vayan encaminadas a los ideales propuestos (p. 58)

Lo anterior pone en contexto varios elementos que tienen que ver con la colaboración mutua, la cual es necesaria en una comunidad educativa, por tanto es posible que un líder de una organización distinta a la educativa proyecte una meta que revele resultados cuantitativos y que para lograrlos requiera de un gran esfuerzo personal, pero para el caso educativo los progresos y alcances serán siempre inmateriales por lo que es necesaria la movilización y acompañamiento de todos los agentes. Si bien en el personal directivo recae la responsabilidad de dirigir la institución sin el respaldo y trabajo de los demás será una tarea difícil de lograr.

Finalmente, el neuroliderazgo se asume como una estrategia para formalizar a través de un análisis in situ las actitudes y competencias de los rectores que dirigen y llevan a cabo el progreso de las instituciones educativas bien sean de carácter rurales o no, por lo tanto, es posible establecer que para todo proceso de gestión directiva se requiere de criterios de liderazgo que ponen en evidencia los aciertos y desaciertos que son necesarios para comprender la realidad educativa, y poder a partir del andamiaje cognitivo-emocional del líder plantear posibles propuestas de mejoramiento.

\section{2 Áreas de enfoque del neuroliderazgo}

Las áreas de enfoque del neuroliderazgo, se constituyen en las aristas que explican y caracterizan las competencias de un líder, por tanto, estas se exponen como principios necesarios para comprender su dinamismo y cualidades que lo definen. En este sentido, es necesario valorar los aportes de Arana (2012), Vázquez (2016) y Bazán (2017), quienes de manera particular han establecido criterios conceptuales a través de los cuales es posible relacionar aspectos cognitivos y emocionales como la toma de decisiones, la motivación, la creatividad, el trabajo en equipo y la gestión emocional, como atributos que develan y argumentan las aptitudes de un líder. A continuación se presentan los siguientes aspectos.

\subsubsection{Toma de decisiones}

Esta área de enfoque corresponde a uno de los aspectos fundamentales a través de los cuales un líder puede considerarse exitoso o no; es de destacar que esta es una de las que podrían llamarse realidades a las cuales se enfrenta continuamente un rector por lo que 
requiere de un grado de motivación para tomar decisiones que se consideren determinantes en su ejercicio directivo. A juicio de Bazán (2017),

La neurología ha entrado en el campo del estudio de la conducta del líder a partir de los conocimientos de su cerebro y fisiología, desde donde las neuronas se activan en la toma de decisiones hasta la forma de conducirse en todas sus gestiones...esto es ver al líder dentro del funcionamiento de sus capacidades neuronales para diferentes misiones. (p. 56)

En ese sentido, se puede decir que la toma de decisiones y el aprendizaje representan la configuración de una red interconectada de neuronas que permiten de manera natural o biológica que el individuo logre ejercer con mayor satisfacción y beneficio sus funciones, considerándose así que en todo proceso cerebral se lleva a cabo un sistema de comunicación e interrelación de neuronas, por medio de las cuales es posible aprender y por consiguiente producir conocimientos y emociones que le conllevan al desencadenamiento de acciones particulares. De forma específica (Vázquez, 2016), plantea que:

La autodeterminación se ve expresada en la capacidad de tomar decisiones a partir del conocimiento de necesidades y posibilidades, así como la implicación personal y el compromiso que requiere la decisión tomada. De esta manera, la autodeterminación se nutre de la integración de distintas dimensiones que posibilitan la elección estas son una dimensión funcional: perspectiva mediata expresada en proyectos profesionales estructurados...y una dimensión motivacional: motivación profesional y satisfacción con la elección profesional (p. 4)

En relación con lo planteado, es posible referir que la motivación surge no solo con el propósito de alcanzar un objetivo particular que se encuentra externo al sujeto, sino que por el contrario nace de sí mismo como un impulso permanente por su propia autorrealización, en este aspecto podría considerarse una cualidad importante en aquellos sujetos, que se reconocen a sí mismo como líderes, y que no necesariamente, requieren de un objetivo específico para trabajar hacia el éxito en su desempeño, por lo que es probable que unida a esta motivación se encuentren elementos axiológicos como la responsabilidad y el compromiso por lo que se hace y lo que se quiere lograr como una meta personal. 


\subsubsection{Resolución de problemas}

Este enfoque se corresponde con la capacidad de establecer procesos acertados para la solución de conflictos, una de las áreas de enfoque del neuroliderazgo con mayor importancia, dado que se establece cierta relación entre la toma de decisiones y la habilidad de negociar. Para Damiano (2011, p.1), desde el neuroliderazgo se explica cómo la gente toma decisiones, resuelve problemas, maneja el cambio, colabora con otros más eficientemente y maneja sus emociones en forma acertada, conllevando a comprender sus reacciones, convirtiéndose en una condición sine qua non para dirigir los recursos y la energía humana de una manera exitosa frente a la resolución de problemas.

Lo referido por la autora, valida la idea de que las habilidades de un líder son mediadas y construidas a través de un proceso complejo y sistemático que se da precisamente en la acción, es decir en el contexto mismo donde desarrolla sus capacidades. Por otra parte, algunos autores consideran que,

La resolución de problemas propiamente dicha implica la búsqueda racional de una solución o soluciones a través de una serie de estrategias que ayudan a solucionar o afrontar una situación problemática. Se consideran cuatro habilidades básicas: 1) definición y formulación del problema, 2) generación de soluciones alternativas, 3) toma de decisión, y 4) aplicación de la solución y comprobación de su utilidad (Bados y García, 2014, p. 5)

En este orden de ideas, queda expuesta la variación de las habilidades básicas que coexisten de manera articulada, con miras a potenciar la toma de decisiones y la motivación para la resolución de conflictos en el plano organizacional, aspecto que humanamente debe trascender hacia la comprensión de las situaciones que rodean las funciones del líder, y es a partir de esa comprensión que se logra establecer una negociación efectiva para solucionar y mejorar los procesos que representan desafíos que exigen propuestas de mejora continua.

\subsubsection{Trabajo en equipo}

El trabajo en equipo representa más que un proceso de acciones desarrolladas colaborativamente, la posibilidad de establecer relaciones de trabajo sostenible, a través de cual se reconocen como miembros aquellos sujetos con los que se comparte una meta $u$ objetivo común; es por ello que una de las áreas de enfoque del neuroliderazgo se centra en 
comprender como un líder logra motivar y establecer relaciones entre sujetos que activamente contribuyen para alcanzar un propósito colectivo.

A partir de lo anterior se puede decir que el trabajo en equipo requiere de unas cualidades de empatía debido a que es evidente, que a nadie le gusta trabajar con los líderes irritables, dominantes o fríos. Sin embargo, aquellos que mantienen un liderazgo optimista y entusiasta suelen conservar durante mucho más tiempo la atención e interés de sus empleados. Lo anterior corresponde a considerar que se requiere de una adecuada gestión emocional para lograr liderar a otras personas, como una habilidad necesaria para alcanzar los logros que sean dispuestos. Por otro lado Ferraros (2002), refiere que,

Los miembros del grupo adjudican a un integrante un rol de portavoz, chivo emisario, líder, etc. Será necesario que el integrante asuma el rol, se "haga cargo". Este juego de adjudicación y asunción de roles se da en la interacción entre estos miembros de esta institución. En otras palabras, líder es la persona que entiende qué necesita el grupo y propone un camino creíble para resolver esa necesidad. Si la situación o los miembros cambian, el líder puede dejar de serlo en otro momento, así como puede no serlo en otro grupo. (p. 5)

Lo anterior hace referencia a la importancia de establecer roles y compromisos en medio de los procesos, como una manera no de condicionar obligaciones, sino de establecer un trabajo organizado y comprometido, atribuyendo a demás elementos éticos como la responsabilidad y el sentido de pertenencia, por cuanto lo que se presente más que definir un líder dirija, lo que se busca es un referente que además de motivar logre concretar acciones y planes a seguir.

\subsubsection{Gestión emocional}

La gestión emocional puede concebirse como la manera a través de la cual el líder asume una conducta pensada y orientada hacia el desarrollo de acciones previamente establecidas, y de las cuales logra obtener beneficios para sí mismo y para los demás, en este aspecto se señala fundamentalmente, la capacidad para reconocerse como sujeto dotado de capacidades que lo hacen diferente, con méritos para lograr objetivos y hacer que otros también los logren. Posturas teóricas como las de Rojas y Gaspar (2006), plantean que: 
Desde el punto de vista biológico las emociones se definen como las disposiciones corporales dinámicas que definen los distintos dominios de acción en que nos movemos. De ahí que cuando uno cambia de emoción cambia de dominio de acción. Es decir si cambian nuestras circunstancias emocionales cambia nuestra forma de razonar. Por ello se considera que nuestra racionalidad se fundamenta en la realización de operaciones condicionadas por la dimensión emocional. En cierta manera se considera que la conciencia y el pensamiento se originan desde la disposición emocional que filtra la realidad (p. 81)

De lo anterior, es posible precisar que la gestión emocional corresponde en cierto modo a la interacción entre elementos emocionales y cognitivos que llevan al sujeto a experimentar sentimientos que de forma categórica condicionan su actuar. Es por ello que podría decirse que líder reconoce la prioridad de sus funciones y acciones por tanto gestiona y enfoca sus emociones hacia sus objetivos, siendo esta una característica fundamental a través de la cual es posible que el líder logre todo lo propuesto.

Algunos autores han generado aportes con respecto algunas teorías asociadas a las emociones, entre ellos Bericat (2012), quien basado en la teoría de las expectativas de Turner y Stets, (2006), plantea que la valoración de un mismo objeto, hecho o persona dependerá de las expectativas previas que tenga el sujeto, lo que puede modificar la experiencia emocional resultante. En el ámbito de la interacción social, un factor clave es si los individuos están a la altura de las expectativas que despiertan en los otros según cual sea su posición de poder o estatus.

Lo expuesto por el autor puede concebirse como una realidad emocional que puede experimentar un líder y más aún cuando cumple una función directiva, dado que las sujetos a su cargo esperan evidenciar sus competencias y alcanzar logros. Es por ello que se requiere de cierto manejo integral y eficiente de los sentimientos y emociones, de manera que las acciones ejecutadas en relación con estas sean las mejores, y lograr así cumplir en cierto modo con las expectativas que toda una comunidad puede tener con respecto a su desempeño.

\subsection{Estilo de liderazgo}

Para distinguir las distintas formas de liderazgo del directivo en la gestión de una organización educativa, se hizo necesario categorizarlos según criterios que refieren la literatura en el área. En este sentido, según Cortes (2004), "el estilo de liderazgo que 
requieren los educadores, se acerca más a un estilo democrático, donde la participación, la confianza y el respeto son elementos fundamentales en la interacción" (p.206).

De allí entonces que analizar las formas y/o dimensiones de liderazgo, permite distinguir una serie de características y acciones que definen la variedad de líderes, como una forma de aceptar la heterogeneidad de los sujetos que comandan proyectos y organizaciones. En este sentido, se plantea mediante la siguiente matriz los siguientes estilos que pudiesen evidenciarse mediante el desempeño del líder educativo.

Tabla 1

Matriz conceptual sobre estilos de liderazgo según sus tendencias

ESTILO DE LIDERAZGO

\begin{tabular}{|c|c|}
\hline Carismático & $\begin{array}{l}\text { El carisma de la gente en el contexto laboral, amerita el reconocimiento } \\
\text { de sus cualidades, capacidades y limitantes frente a la gestión } \\
\text { directiva. En este sentido, la dimensión carismática del liderazgo, se } \\
\text { concibe como la esencia innata del ser humano, que no es transferible } \\
\text { ni mucho menos replicable, por cuanto son atributos legítimos de cada } \\
\text { uno de los miembros de una institución, lo que demuestra la } \\
\text { divergencia de estilos y/o formas de gerencia. }\end{array}$ \\
\hline Emocional & $\begin{array}{l}\text { Para Pozueta (2015), el liderazgo emocional se basa en el desarrollo } \\
\text { de las emociones clave que todo líder debe tener para influir, } \\
\text { desarrollar, animar, identificar y lanzar a su equipo hacia la } \\
\text { consecución de sus metas y objetivos. } \\
\text { En ese sentido, el factor emocional recobra una gran fuerza ante la } \\
\text { pretensión de persuadir a otros para el logro de ciertos objetivos y/o } \\
\text { metas organizacionales, donde la comprensión, la empatía, la } \\
\text { comunicación asertiva, el desarrollo de habilidades interpersonales e } \\
\text { intrapersonales, dentro y fuera de la institución se convierten en los } \\
\text { pilares fundamentales. }\end{array}$ \\
\hline Participativo & $\begin{array}{l}\text { Con miras a una gestión directiva integrada con todos los miembros de } \\
\text { la institución, se asume el estilo de liderazgo participativo como la } \\
\text { forma de involucrar y escuchar todas las voces de la organización, a fin } \\
\text { de enrumbarla a su misión y visión para el alcance de sus objetivos } \\
\text { propuestos. Dicho ejercicio del líder, comulga con un espacio abierto, } \\
\text { democrático y transformador donde las apreciaciones y acciones del } \\
\text { colectivo juegan un papel predominante en actividades asociadas con } \\
\text { la formulación de presupuesto, toma de decisiones, entro otros } \\
\text { procesos relacionados con la efectividad, eficiencia y calidad del } \\
\text { servicio brindado. }\end{array}$ \\
\hline Emergente & $\begin{array}{l}\text { Aun cuando no se constituyó en una unidad de medición en el estudio } \\
\text { abordado, este estilo de liderazgo, se asocia con el desempeño del } \\
\text { rector desde una perspectiva centrada en el pensamiento sistémico, } \\
\text { donde prevalece el abordaje de situaciones emergentes bajo premisas } \\
\text { de incertidumbre y probabilidades. Sus herramientas se destinan a la } \\
\text { integración de todos los estilos anteriores. }\end{array}$ \\
\hline
\end{tabular}

Fuente: Atencio, Ramírez y Zappa (2019)

Dada la matriz anterior, se tiene que la variación entre un estilo de liderazgo y otro, dependerá de las cualidades, aptitudes y capacidades del rector, conforme a su estilo de 
pensamiento, actuación y visión sobre el mundo de la gestión que emprenderá, aun cuando sistémicamente, la tendencia apunta a la integración de todos los estilos abordados anteriormente conforme a las necesidades de las instituciones educativas, y su personal.

\subsection{Habilidades directivas}

Para el desarrollo y logro de una práctica gerencial pertinente frente a las exigencias del contexto educativo postmoderno, se hace necesario que el director(a), reconozca y desempeñe las diversas habilidades que se requieren para la consecución de logros frente a la gestión que se ha planteado en el marco del proyecto educativo institucional. Para tal fin, en el presente artículo se asumió el abordaje de la comunicación empática, la innovación y la planificación estratégica, como tres ejes que se apoya y complementan para la concreción del ejercicio del líder, donde la neuroplasticidad, el neuroaprendizaje y la capacidad atencional, juegan un papel preponderante frente al desencadenamiento de conductas que desde la perspectiva neurocientifica explican el comportamiento del gerente educativo en cuanto a procesos vinculados con la toma de decisiones, resolución de problemas, entre otros. Desde esta perspectiva, se presentan a continuación los rasgos conceptuales que apuntan a cada una de las habilidades tratadas en el marco de la investigación.

Tabla 2

Matriz conceptual sobre habilidades directivas según fines del neuroliderazgo

\section{HABILIDAD DIRECTIVA CONCEPTUALIZACIÓN}

Para que en las organizaciones modernas se logren los objetivos estipulados, se deben promover espacios de participación dialógica entre todos sus actores, a fin de alcanzar desde una acción comunicativa, el proceso de toma de decisiones pertinentemente en Comunicación empática cuanto a las necesidades que ameritan ser resultas. Es por ello, que la comunicación empática se constituye en una habilidad elemental del director de una comunidad educativa, por cuanto le posibilita persuadir, interpretar y comprender las realidades de cada integrante como un todo integrado.

La necesidad de reinventar, restructurar, o renovar el contexto de la gestión directiva desde la nuevas tendencias, entre estas, el neuroliderazgo, es imperante que el director o líder educativo, Innovación $\quad$ promueva el desarrollo del potencial creativo e innovador del personal, con miras a la redefinición de su praxis tanto pedagógica como administrativa, para responder a las necesidades emergentes del contexto al cual se debe la institución.

Habilidad indispensable que debe desempeñar todo gerente educativo, por cuanto le posibilita estimar las condiciones presentes y futuras que conducen el logro de los objetivos institucionales, mediante la

Planificación estratégica concreción de actividades cónsonas con la realidad del contexto escolar, los objetivos, misión, visión y valores que rigen la dinámica organizacional desde la perspectiva del líder y su equipo de trabajo.

Fuente: Atencio, Ramírez y Zappa (2019) 
En síntesis, se puede decir que las habilidades de comunicación empática, innovación, planeación estratégica, entre otras muchas más, brindan un horizonte que contempla un sinfín de herramientas, para el logro de los objetivos de la organización educativa que buscan responden con criterios de eficiencia, eficacia y efectividad a las nuevas tendencias educativas y gerenciales, desde una perspectiva centrada en los adelantos científicos en el área.

\section{Metodología}

\subsection{Enfoque}

El modelo epistémico asumido apuntó a los planteamientos filosóficos del paradigma empírico analítico de enfoque cuantitativo, con el propósito de efectuar registros objetivos de la realidad de estudio asociada al neuroliderazgo en la gestión directiva en la Institución Educativa objeto de estudio, a partir de la observación y descripción de los hechos centrados en la medición de la variable, sus dimensiones e indicadores para alcanzar el logro de los objetivos estipulados, y de tal manera responder la interrogante que condujo el estudio.

En este marco de referencia, se empleó una tipología de investigación proyectiva, considerando que su intención se centró en proponer estrategias basadas en el neuroliderazgo para el fortalecimiento de la gestión directiva en la institución educativa referida, a partir de la caracterización de los rasgos más perceptibles sobre las áreas de enfoques, estilos de liderazgo y habilidades directivas demostradas por el personal involucrado, con miras de generar una alternativa que contribuya a la solución de la problemática planteada.

En cuanto al diseño, se asumió la estrategia de campo tomando en cuenta que los datos fueron tomados directamente en el contexto de la institución educativa objeto de estudio conservando su estado natural, es decir, sin manipulación alguna de los acontecimientos, lo que también le atribuye un carácter no experimental. En este sentido, la elección de la estrategia obedeció a la naturaleza de los objetivos de investigación planteados, los cuales apuntaron a situaciones meramente de descripción para alcanzar la formulación de estrategias basadas en neuroliderazgo.

\subsection{Población de estudio}

La población estuvo integrada por el personal directivo (a) y docente de la Institución Educativa Pueblo Bujo de Montería, Córdoba - Colombia, cuantificado por un total de 40 
sujetos. Es de gran relevancia destacar, que dado el reducido tamaño de la población y la posibilidad de acceso a la totalidad de la misma, no fue necesario calcular el tamaño muestral asumiendo así la población total, lo que Tamayo y Tamayo (2008), denomina censo poblacional. Dicho estudio se efectuó durante el año escolar 2017-2018, contemplando su fase de planificación y operativa metodológica. A continuación se muestra la tabla 1, en la cual se contempla la caracterización de la población.

Tabla 3

Caracterización de la población de estudio por funciones docentes desempeñadas, año escolar 2018-2019

\begin{tabular}{|c|c|}
\hline DESCRIPCIÓN & CANTIDAD \\
\hline Personal directivo(a) & $\mathbf{2}$ \\
\hline Docentes de aulas & $\mathbf{3 8}$ \\
\hline TOTAL & $\mathbf{4 0}$ \\
\hline
\end{tabular}

Fuente: Atencio, Ramírez y Zappa (2019)

\subsection{Técnicas de recolección}

La técnica e instrumento de recolección de datos según Chávez (2009), es el medio que se utiliza para medir el comportamiento de la variable de estudio. Visto así, la recolección de la información se realizó con base en la técnica de la encuesta y un cuestionario como instrumento. A continuación se refleja la matriz de operacionalización.

Tabla 4

Operacionalización de la variable según dimenisones e indicadores de medición en la población de estudio, año escolar 2018-2019

\begin{tabular}{|c|c|l|}
\hline \multirow{2}{*}{ VARIABLE } & \multicolumn{2}{|c|}{ DIMENSIONES } \\
\hline \multirow{2}{*}{$\begin{array}{c}\text { Neuroliderazgo en la } \\
\text { gestión directiva }\end{array}$} & $\begin{array}{c}\text { Áreas de enfoque del } \\
\text { neuroliderazgo }\end{array}$ & $\begin{array}{l}\text {-Toma de decisiones } \\
\text {-Resolución de problemas } \\
\text {-Trabajo en equipo } \\
\text {-Gestión emocional }\end{array}$ \\
\cline { 2 - 3 } & Estilo de liderazgo & $\begin{array}{l}\text {-Carismático } \\
\text {-Emocional } \\
\text {-Participativo }\end{array}$ \\
\cline { 2 - 3 } & $\begin{array}{l}\text { Habilidades } \\
\text { directivas }\end{array}$ & $\begin{array}{l}\text {-Comunicación empática } \\
\text {-Innovación } \\
\text {-Planificación estratégica }\end{array}$ \\
\hline
\end{tabular}

Fuente: Atencio, Ramírez y Zappa (2019)

Para la construcción del instrumento mencionado, se generó en función de cada uno de los indicadores considerados en la investigación tres (3) ítems, con el fin de garantizar la 
coherencia entre variable, dimensiones, indicadores e ítems. El instrumento en este sentido, estuvo conformado por 33 ítems, con una escala de respuesta cerrada tipo Likert, de cinco alternativas, a saber: siempre, casi siempre, algunas veces, casi nunca y nunca.

El instrumento, se aplicó previo consentimiento informado del personal involucrado, y a su vez, previo proceso de validación de contenido a través de la técnica del Juicio de Expertos, según tres (3) profesionales en el área de investigación y gerencia. En cuanto a la confiabilidad del mismo, se calculó mediante el Coeficiente de Cronbach, cuyo resultado se reflejó un coeficiente de 0.83 , indicando una alta confiabilidad.

\subsection{Procesamiento de análisis}

El análisis de los resultados de los objetivos se realizó a través del método de estadística descriptiva, empleando las Técnicas de Medidas de Tendencia Central, a través del promedio y las Medidas de Variabilidad, utilizando la desviación estándar.

Asimismo, para la presentación de los resultados se diseñó una serie de tablas por dimensiones e indicadores, que muestran las medidas utilizadas para los fines del análisis con sus respectivos valores, arrojados a través del procesamiento de datos. En este marco de referencia, para la construcción del baremo de interpretación del promedio se tomó en consideración la valoración cuantitativa asignada a las cinco alternativas de respuesta, a saber: Siempre (5), Casi Siempre (4), A Veces (3), Casi Nunca (2) y Nunca (1), para luego definir los intervalos. En ese sentido, el uso de la media permitió la categorización de ítems, indicadores, dimensiones y variable de estudio. Sobre esta base, para su interpretación fue diseñada por los investigadores una tabla de rango, intervalo y categoría. Seguidamente se muestra la tabla 5 donde se configura la categoría de análisis del promedio.

\section{Tabla 5}

Análisis del promedio según criterios de rango, intervalo y categoría de las respuestas de la población de estudio, año escolar 2018-2019

\begin{tabular}{|c|c|c|}
\hline RANGO & INTERVALO & CATEGORÍA \\
\hline 1 & $4.21-5$ & Muy Alto \\
\hline 2 & $3.41-4.20$ & Alto \\
\hline 3 & $2.61-3.40$ & Moderado \\
\hline 4 & $1.81-2.60$ & Bajo \\
\hline 5 & $1-1.80$ & Muy Bajo \\
\hline
\end{tabular}

Fuente: Atencio, Ramírez y Zappa (2019)

Para la segunda técnica referida a "medida de variabilidad", se utilizó la desviación estándar con el fin de indicar el grado de dispersión de las respuestas, con relación a la 
escala de medición utilizada y su rango, representado por las puntuaciones mayor y menor obtenidos, es decir, cuatro (4) y cero (0) respectivamente, lo cual permitió elaborar para su respectivo análisis la tabla 6 contentiva del rango, intervalo y categoría de interpretación.

Tabla 6

Baremo de interpretación de la desviación estándar según criterios de rango, intervalo y categoría de las respuestas de la población de estudio, año escolar 2018-2019

\begin{tabular}{|c|c|c|}
\hline RANGO & INTERVALO & CATEGORÍA \\
\hline 1 & $3.21-4$ & Muy Alta Dispersión \\
\hline 2 & $2.41-3.20$ & Alta Dispersión \\
\hline 3 & $1.61-2.40$ & Moderada Dispersión \\
\hline 4 & $0.81-1.60$ & Baja Dispersión \\
\hline 5 & $0-0.80$ & Muy Baja Dispersión \\
\hline
\end{tabular}

Fuente: Atencio, Ramírez y Zappa (2019)

\section{Resultados}

Antes de iniciar el proceso operativo de análisis e interpretación de los hallazgos derivados del estudio, es necesario volver la mirada al objetivo general cuya intención se centró en formular estrategias basadas en neuroliderazgo para el fortalecimiento de la gestión directiva en la Institución Educativa Pueblo Bujo del municipio de Montería, CórdobaColombia, en el año 2017-2018. En este sentido, se presentan seguidamente los resultados mediante la descripción de la tabla 7 referida a las dimensiones e indicadores contemplados para la medición de la variable.

\section{Tabla 7}

Resultados de la variable: Neuroliderazgo en la gestión directiva según datos obtenidos del instrumento de recolección aplicado a la la población de estudio, año escolar 2019

\begin{tabular}{|lc|c|c|c|}
\hline \multicolumn{1}{|c}{ DIMENSIONES } & \multicolumn{2}{c|}{ DOCENTES } & \multicolumn{2}{c|}{ DIRECTIVOS (as) } \\
\cline { 2 - 5 } & $\begin{array}{c}\text { Promedi } \\
\mathbf{0}\end{array}$ & $\begin{array}{c}\text { Desviació } \\
\mathbf{n}\end{array}$ & Promedio & Desviación \\
\hline $\begin{array}{l}\text { Áreas de enfoque del } \\
\text { neuroliderazgo }\end{array}$ & 3,36 & 0,71 & 3,43 & $\mathbf{0 , 7 1}$ \\
\hline Estilo de liderazgo & 3,44 & 0,71 & 4,17 & $\mathbf{0 , 7 8}$ \\
\hline Habilidades directivas & 3,91 & 0,69 & 4,10 & $\mathbf{0 , 8 0}$ \\
\hline Promedio general & $\mathbf{3 , 5 7}$ & $\mathbf{0 , 7 0}$ & $\mathbf{3 , 9}$ & $\mathbf{0 , 7 6}$ \\
\hline
\end{tabular}

Fuente: Atencio, Ramírez y Zappa (2019)

Con respecto a la variable neuroliderazgo en la gestión directiva, se obtuvo un promedio en las respuestas de las y los docentes encuestados de 3,57, con una muy baja dispersión de 0,70, ubicándose en la categoría alta, al evidenciar los mismos que el personal directivo desempeña las funciones inherentes al cargo con habilidades directivas idóneas, con un estilo de liderazgo oportuno, y asumiendo las diversas áreas de enfoques del 
neuroliderazgo con ciertas carencias en algunos casos, tal como se puntualiza a continuación. Por su parte, el personal directivo alcanzo una media de 3,9, con una muy baja dispersión de 0,76, ubicándose de igual forma en una categoría alta.

Para dar continuidad al análisis de los resultados, es necesario responder a cada una de las dimensiones de la variable, iniciando en primera instancia con las áreas de enfoque del neuroliderazgo abordadas por el personal directivo de la institución objeto de estudio, el cual se evidencia mediante la interpretación de la tabla 8.

Tabla 8

Resultados de la Dimensión: Áreas de enfoque del Neuroliderazgo, según datos obtenidos del instrumento de recolección aplicado a la la población de estudio, año escolar 2019

\begin{tabular}{|lc|c|c|c|}
\multicolumn{1}{c}{ INDICADORES } & \multicolumn{2}{c}{ DOCENTES } & \multicolumn{2}{c|}{ DIRECTIVOS (as) } \\
\cline { 2 - 5 } & Promedio & Desviación & Promedio & Desviación \\
\hline Toma de decisiones & 3,18 & 0,63 & 4,10 & $\mathbf{0 , 6 8}$ \\
\hline Resolución de problemas & 3,17 & 0,71 & 3,29 & $\mathbf{0 , 7 3}$ \\
\hline Trabajo en equipo & 4,12 & 0,79 & 4,17 & $\mathbf{0 , 7 6}$ \\
\hline Gestión emocional & 2.97 & 0.74 & 3,19 & $\mathbf{0 , 7 2}$ \\
\hline Promedio general & $\mathbf{3 . 3 6}$ & $\mathbf{0 . 7 1}$ & $\mathbf{3 , 6 8}$ & $\mathbf{0 . 7 2}$ \\
\hline
\end{tabular}

Fuente: Atencio, Ramírez y Zappa (2019)

En cuanto a las mencionadas áreas de enfoque del neuroliderazgo, se obtuvo un promedio en las respuestas de las y los docentes encuestados de 3,36, con una muy baja dispersión de 0,71, ubicándose según el baremo de interpretación en la categoría moderada, al evidenciar los mismos que en la Institución Educativa Pueblo Bujo del municipio de Montería, Córdoba-Colombia, el personal responsable de la gestión directiva asumen el proceso de toma de decisiones, resolución de problemas y trabajo en equipo sustentado en la gestión de sus emociones. Por su parte, la opinión del directivo encuestado evidenció una media de 3,68 , con una muy baja dispersión de 0,72 , ubicándose de igual forma en una categoría moderada según el baremo.

Al respecto, los aportes de Arana (2012), Vázquez (2016) y Bazán (2017), permiten identificar diversos criterios conceptuales a través de los cuales es posible relacionar aspectos cognitivos y emocionales como la toma de decisiones, la motivación, la creatividad, el trabajo en equipo y la gestión emocional como atributos que explican y revelan las aptitudes que conforman a un líder, postura que le brinda consistencia a los hallazgos obtenidos.

Sobre los indicadores toma de decisiones y resolución de problemas, se obtuvieron promedios de las respuestas de las y los docentes encuestados de 3,18 y 3,17 , 
respectivamente, con muy bajas dispersiones de 0,63 y 0,71, ubicándose ambos según el baremo de interpretación en la categoría moderada, al evidenciar que la gestión del rector (a) en la institución objeto de estudio no existe participación total de todo los actores escolares en el proceso de toma de decisiones, y consecuentemente, en la resolución de problemas. En el caso de los directivos (as), se obtuvieron promedios de 4,10 y 3,29, con muy bajas dispersiones de 0,68 y 0,73 , lo que permitió ubicar los indicadores en una categoría alta y moderada.

Dichos resultados convergen con la postura teórica de Bazan (2017), quien alude que la neurología ha entrado en el campo del estudio de la conducta del líder a partir de los conocimientos de su cerebro y fisiología, desde donde las neuronas se activan en la toma de decisiones hasta la forma de conducirse en todas sus gestiones...esto es ver al líder dentro del funcionamiento de sus capacidades neuronales para diferentes misiones. No obstante, en cuanto a la resolución de problemas, Damiano (2011), plantea que el neuroliderazgo explica cómo la gente toma decisiones, resuelve problemas, maneja el cambio, colabora con otros más eficientemente y maneja sus emociones en forma acertada, conllevando a comprender nuestras reacciones y las de quienes interactúan con nosotros. Lo anterior argumenta que los indicadores de toma de decisión y resolución de problemas se alinean a los planteamientos teóricos que se asumieron en la construcción del estudio.

En lo que refiere a los indicadores trabajo en equipo y gestión emocional, se obtuvieron promedios de las repuestas otorgados por las y los docentes de 4,12 y 2,97, respectivamente, con muy bajas dispersiones en las respuestas de 0,79 y 0,74, ubicándose ambos según el baremo de interpretación en la categoría alta para el caso del primer indicador y moderada para el segundo, al evidenciar que en la institución objeto de estudio a pesar de que se manifiesta un trabajo colaborativo entre sus miembros, el mismo representa debilidad por el refuerzo emocional del directivo, situación que compromete sus habilidades. Por su parte, los (as) directivos (as) arrojaron unos promedios de 4,17 y 3,19, con muy bajas dispersiones, de 0,76 y 0,72 , lo que indica que para ellos los indicadores tratados se ubican en una categoría alta y moderada respectivamente.

Lo anterior se corresponde con los planteamientos de Escobar (2013), quien señala que dentro de los requisitos para lograr un trabajo en equipo está el de cumplir el desafío de motivar y comprometer a los socios en la organización, haciendo que surjan nuevos desafíos para que cada ingreso a nuevos equipos de trabajo sea acogedor y estimulante, logrando así que cada persona se involucre con total facilidad en cualquier grupo que decida incorporar. Por otro lado, en cuanto a la gestión emocional, Caballero y Blanco (2016), señalan que para 
esta se requiere de cierto grado de voluntad a través del cual sea posible canalizar las emociones vivenciadas en función de un desempeño.

A continuación se muestra la tabla 9, la cual refiere los resultados obtenidos en cuanto a la dimensión estilo de liderazgo, considerando sus indicadores: carismático, emocional y participativo.

\section{Tabla 9}

Resultados de la Dimensión: Estilo de liderazgo, según datos obtenidos del instrumento de recolección de datos aplicado a la la población de estudio, año escolar 2019

\begin{tabular}{|lc|c|c|c|}
\hline \multirow{2}{*}{ INDICADORES } & \multicolumn{2}{c}{ DOCENTES } & \multicolumn{2}{c|}{ DIRECTIVOS (as) } \\
\cline { 2 - 5 } & Promedio & Desviación & Promedio & Desviación \\
\hline Carismático & 4,15 & 0,76 & 4,10 & $\mathbf{0 , 6 9}$ \\
\hline Emocional & 2.99 & 0.74 & 3,18 & $\mathbf{0 , 6 7}$ \\
\hline Participativo & 3,19 & 0,65 & 4,18 & $\mathbf{0 , 6 9}$ \\
\hline Promedio general & $\mathbf{3 . 4 4}$ & $\mathbf{0 . 7 1}$ & $\mathbf{3 , 8 2}$ & $\mathbf{0 , 6 8}$ \\
\hline
\end{tabular}

Fuente: Atencio, Ramírez y Zappa (2019)

Sobre la dimensión estilo de liderazgo, la tabla 9 refleja los resultados derivados de la aplicación del cuestionario a la población docente, cuyas repuestas arrojaron un promedio general de 3.44, con muy bajas dispersiones de 0.71 , lo que según el baremo de interpretación se ubica en una categoría alta, al evidenciarse que el rector de la Institución Educativa Pueblo Bujo del municipio de Montería, Córdoba-Colombia, desempeña sus funciones desde las dimensiones carismática y participativa, con debilidades en la emocional, lo que permite comprobar los planteamientos de Cortes (2004), quien alude que "El estilo de liderazgo que requieren los educadores se acerca más a un estilo democrático, donde la participación, la confianza y el respeto son elementos fundamentales en la interacción". Por su parte, el personal directivo encuestado reflejo un promedio de 3,82, con una muy baja dispersión de 0,68, ubicándose de igual manera en una categoría alta.

En cuanto al indicador carismático, se obtuvo según las repuestas otorgadas por las y los docentes de la institución objeto de estudio, un promedio de 4,15, con muy baja dispersión de 0,76, lo que según el baremo de interpretación el indicador tratado se ubica en la categoría alta, al evidenciarse que el ejercicio laboral del rector contempla la empatía, la escucha activa y el respeto por el papel que cada miembro de la comunidad escolar desempeña ante la ejecución de las tareas asignadas. Aunado a ello, los puntajes de la persona directiva reflejó una media de 4,10, con una muy baja dispersión de 0,69, ubicándose en una categoría alta. 
Desde este punto de vista, se puede decir que el rector, según Ganga y Navarrete (2014), está constituido por una serie de características y cualidades llamativas y auténticas, que hacen único, excepcional y extraordinaria a una persona; es decir, se está hablando de condiciones que le posibilitan al sujeto generar atractividad y magnetismo, posición que le permite cautivar de forma natural a sus seguidores. En ese sentido, es notoria la correspondencia que existe entre dicho estilo del rector de la institución y los argumentos conceptuales que respaldan este indicador de liderazgo, el cual según la tabla 1, plantea que el carisma de la gente en el contexto laboral, amerita el reconocimiento de sus cualidades, capacidades y limitantes frente a la gestión directiva.

Sobre los indicadores emocional y participativo, se obtuvo un promedio de 2,99, y 3,19, respectivamente, con muy baja dispersión de 0,74 y 0,65, ubicándose ambos resultados según el baremo de interpretación en una categoría moderada, al evidenciarse que el (la) directivo (a) de la Institución Educativa Pueblo Bujo, no desempeña sus funciones articulando sus potenciales cognitivos y emocionales para el logro de los objetivos de la organización, aun cuando este, busca e implementa las estrategias para alcanzar una visión compartida desde la participación de todos los actores que hacen vida en la institución. Por su parte, el (la) directivo (a) reportó una media de 3,18, y 4,18 respectivamente, con una muy baja dispersión de 0,67, y 0,69, ubicándose en una categoría moderada y alta.

En este orden de ideas, cobran fuerza los planteamientos de Pozueta (2015), quien refiere que el liderazgo emocional se basa en el desarrollo de las emociones clave que todo líder debe tener para influir, desarrollar, animar, identificar y lanzar a su equipo hacia la consecución de sus metas y objetivos. Por otras parte, en cuanto al liderazgo participativo, Vargas (2003), citado por Cortez (2004), plantea que este está fundamentado en la cultura de la participación, donde el líder crea condiciones para que sus compañeros colaboren con él en la definición de la misión, les hace partícipes de su visión y crea un consenso sobre los valores que deben dar estilo a la organización.

Continuando con el análisis de los datos, es menester responder a las habilidades directivas demostradas por el rector de la institución educativa objeto de estudio, el cual se detalla mediante la tabla 10 a continuación. 
Tabla 10

Resultado de la Dimensión: Habilidades directivas según datos obtenidos del instrumento de recolección aplicado a la la población de estudio, año escolar 2019

\begin{tabular}{|lc|c|c|c|}
\hline \multicolumn{1}{c}{ INDICADORES } & \multicolumn{2}{c}{ DOCENTES } & \multicolumn{2}{c|}{ DIRECTIVOS (as) } \\
\cline { 2 - 5 } & PROMEDIO & DESVIACION & PROMEDIO & DESVIACION \\
\hline Comunicación empática & 4,19 & 0,73 & 4,17 & $\mathbf{0 , 6 9}$ \\
\hline Innovación & 3,41 & 0,59 & 4,10 & $\mathbf{0 , 7 0}$ \\
\hline Planificación estratégica & 4,14 & 0,77 & 4,29 & $\mathbf{0 , 7 8}$ \\
\hline Promedio general & $\mathbf{3 , 9 1}$ & $\mathbf{0 , 6 9}$ & $\mathbf{4 , 1 8}$ & $\mathbf{0 , 7 2}$ \\
\hline
\end{tabular}

Fuente: Atencio, Ramírez y Zappa (2019)

Sobre la dimensión Habilidades directivas, la tabla 10 refleja los resultados derivados de la aplicación del cuestionario a los y las docentes, cuyas repuestas arrojaron un promedio general de 3,91, con muy baja dispersión de 0.69, lo que según el baremo de interpretación se ubica en una categoría alta, al evidenciarse que el rector de la Institución Educativa Pueblo Bujo del municipio de Montería, Córdoba-Colombia, refleja habilidades para propiciar la comunicación empática, innovación y planificación estratégica institucional. Por su parte, el (la) directivo (a) reflejo un promedio de 4,18, con una muy baja dispersión, de 0,72, ubicándose en una categoría alta.

Desde esta perspectiva, se retoma la conceptualización de Schmelkes, (2000), quien hace mención que las habilidades directivas apuntan al grado en que el director de la escuela es capaz de generar una definición colectiva y dinámica de las diversas formas de lograr adecuadamente el objetivo central de una escuela. Dichas formas tienen que ver necesariamente con la manera como se tomen las decisiones y, sobre todo, con el tipo de interrelaciones que el centro promueva, favorezca, acepte, tolere, rechace o sancione.

En cuanto a los indicadores comunicación empática e innovación, se obtuvieron sobre la base de las y los docentes encuestados unos promedios de 4,19, y 3,41, respectivamente, con muy baja dispersión de 0,73 y 0,59, lo que según el baremo de interpretación permite ubicar a ambos indicadores en al categoría alta, al evidenciarse que la gestión directiva en la institución objeto de estudio contempla escenarios aceptables para el desarrollo comunicacional basados en el respeto de los canales y medios dispuestos para tal fin, donde además se pone de manifiesto la capacidad de inventiva, redefinición y originalidad ante los procesos gerenciales abordados. Por su parte, el (la) directivo (a) reflejo promedios de 4,17 y 4,10 para ambos indicadores, con muy baja de dispersión de 0,69 y 0,70 respectivamente, ubicándose en una categoría alta. 
Dado lo anterior, para Weinstein (2002), es fundamental el reconocimiento de los espacios para la comunicación y la participación, por medio de los cuales se haga evidente la toma de decisiones en el marco de una acción comunicativa conjunta que ponga en balance las necesidades y aspiraciones de toda la comunidad en general. Aunado a ello, sobre la innovación, Cuglievan, y Rojas (2008), plantean que un aspecto de mayor relevancia de la gestión directiva tiene que ver con la capacidad de desarrollar acciones de seguimiento y continuo mejoramiento para el alcance de las metas o propósitos institucionales, teniendo en cuenta que para el logro de los objetivos se requiere de aspectos innovadores a través de los cuales se retroalimenten los procesos directivos y educativos.

Finalmente sobre el indicador planificación estratégica, se obtuvo de las repuestas otorgadas por las y los docentes un promedio de 4,14, con muy baja dispersión de 0,77 , lo que según el baremo de interpretación permite ubicar este indicador en una categoría alta, al ponerse de manifiesto la capacidad del personal directivo de la institución objeto de estudio para concretar el proyecto educativo institucional a partir de la misión, visión, objetivos y valores que lo constituyen. Por su parte, el personal directivo refirió un promedio de 4,29, con muy baja dispersión de 0,78, ubicándose en una categoría muy alta.

De tal manera, es oportuno volver la mirada a los planteamientos de Corredor (2007), quine refiere que la planificación es un proceso integral que propone una nueva actitud hacia el futuro, mediante la aplicación de normas que incluyan la razón organizacional, la relación de actores antagónicos, la cualidad del proceso y las perspectivas de cambio. Desde esta perspectiva, no solo es posible hablar de estilos de liderazgo sino también de planificación estratégica como referente necesario para el desarrollo de habilidades directivas.

En atención a los resultados emergentes del proceso de análisis e interpretación efectuado, se presenta a continuación un conjunto de estrategias configuradas a partir de los componentes del neuroliderazgo, con el fin de fortalecer las debilidades detectadas mediante los hallazgos de la investigación, permitiendo concebirlas con énfasis en la neuroplasticidad, en el neuroaprendizaje y en la capacidad atencional del personal. En atención a ello, se contempla la propuesta denominada: Neuroliderazgo: Potenciando habilidades directivas en contextos educativos.

\subsection{Regeneración celular para la liderazgo desde la Neuroplasticidad}

Para Dispeza (2007), la neuroplasticidad se concibe como "la capacidad del cerebro de reformarse, remodelarse y reorganizarse". Se puede conceptualizar como la habilidad del 
cerebro de modificar o alterar su propia estructura como consecuencia de la experiencia y del pensamiento, para adaptarse a los cambios que el entorno impone o para funcionar de otro modo. El cerebro, tiene la propiedad de conocer y adaptarse a la actividad que realiza. De modo que modificando la actividad que se realiza se puede modificar la estructura del cerebro. Seguidamente se presenta la figura 1, contentiva de las estrategias formuladas haciendo énfasis en la neuroplasticidad.

Figura 1. Estrategias con énfasis en neuroplasticidad.

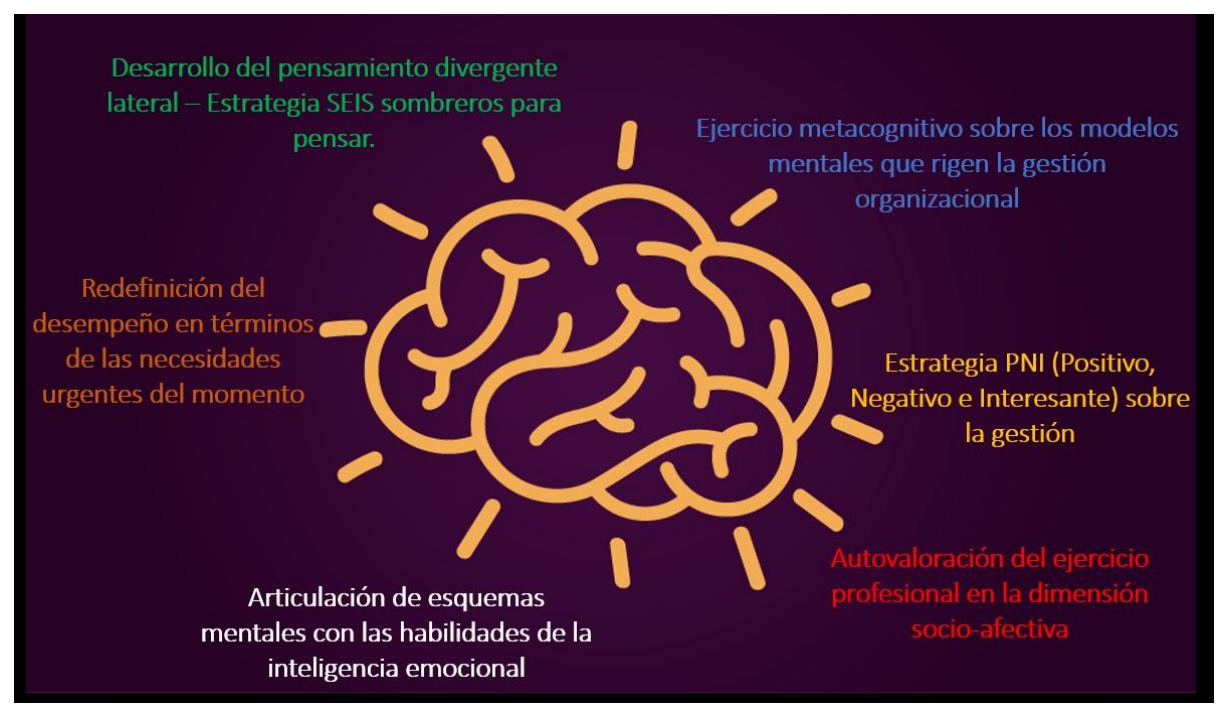

Fuente: Atencio, Ramírez y Zappa (2019)

Atendiendo a los resultados de la investigación y las estrategias contempladas en la figura 1, se busca estimular y potenciar el desarrollo de nuevos escenarios en el contexto de la gerencia educativa, partiendo de la interconexión de ideas, situaciones o vivencias entretejidas entre el rector y el docente, donde la regeneración celular, de lugar a comportamientos emergentes frente al proceso de cambio en el plano organizacional (interacción) y personal (accionar de la gente), lo que conduce desde la praxis a desaprender para aprender nuevas estructuras funcionales que el cerebro controla y domina.

En relación a lo anterior, Atencio (2015), afirma que las nuevas esferas glocales del conocimiento y sus aplicaciones en el ámbito gerencial, han dispuesto de estructuras fuera de la lógica lineal, enmarcadas en la complejidad del pensamiento, y por ende, en el desarrollo de prácticas eficaces y eficientes para la generación del cambio, y consecuentemente, la reingeniería de procesos tildados por el accionar de la gente, 
asumiéndose esta como el principal y mayor recurso de significancia para el logro de la productividad y competitividad en la aldea global.

\subsection{Interconexión de ideas y vivencias del líder desde el neuroaprendizaje}

Según Dispeza (2007), el neuroaprendizaje refiere a una disciplina que nació de la conjunción de varias ciencias como la neurobiología, la psicología y la pedagogía, entre otras. El neuroaprendizaje estudia al cerebro "como órgano del aprendizaje"; su anatomía, funcionalidad y plasticidad que hace posible los procesos de aprendizaje. Algunos de los aportes interesantes del neuroaprendizaje, que pueden ser capitalizables en la gestión del liderazgo, son: Aprendizaje por asociación y por experiencia.

En virtud del basamento anterior se presenta a continuación la figura 2 donde se ilustran las diversas estrategias propuestas frente a la necesidad de fortalecer la interconexión de ideas y vivencias del líder desde el neuroparendizaje.

Figura 2. Estrategias con énfasis en neuroaprendizaje.

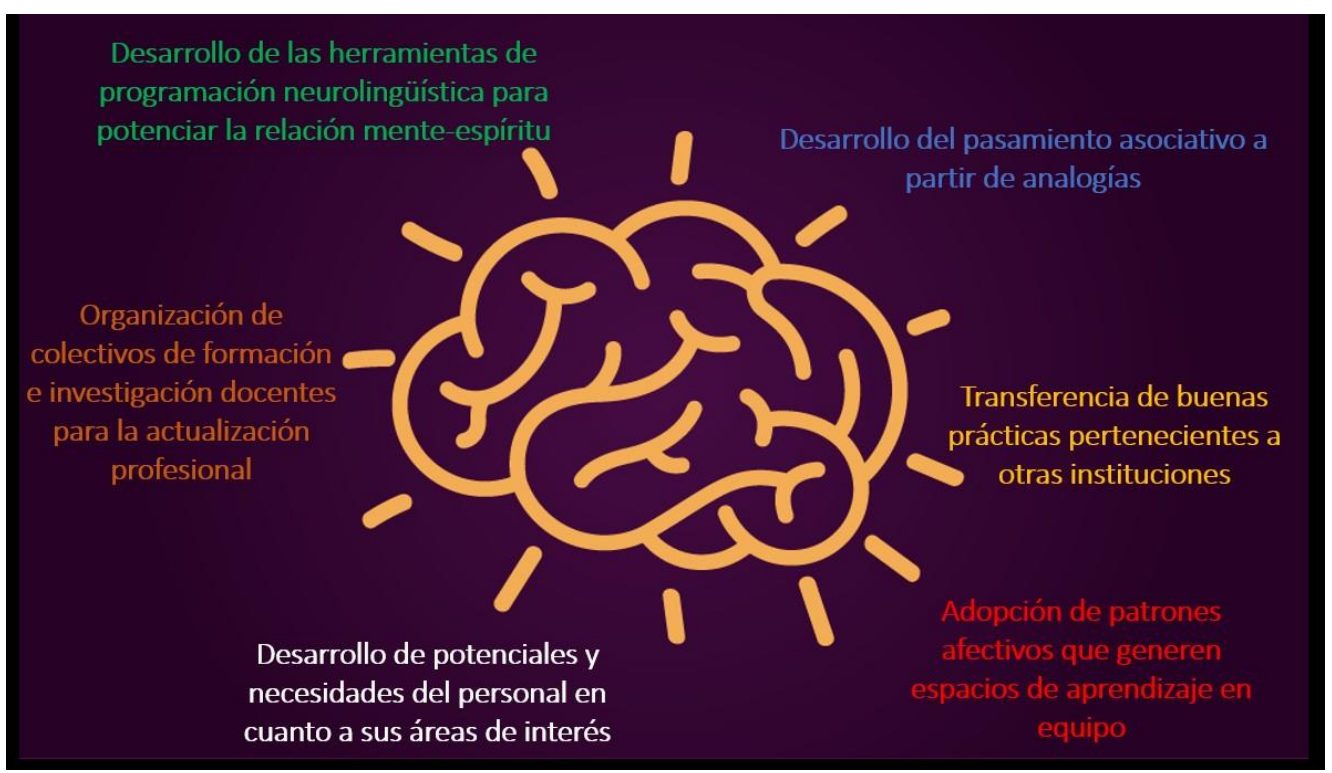

Fuente: Atencio, Ramírez y Zappa (2019)

Tal como se ha expresado a lo largo de este artículo, la función y/o habilidades del líder, que para otros, se conciben como competencias, demandan capacidad para aprender a desaprender, y de este modo, reaprender nuevas situaciones, procesos o vivencias, que definen el rumbo del estilo de liderazgo que se ha de asumir durante la gestión educativa. Sin embargo, desde el campo de la neuroeducación, y por ende, del neuroaprendizaje, se 
busca situar, estimular y ejercitar los procesos cognoscitivos que como líder-gerente hacemos conscientes mediante el compromiso de dirigir la organización al logro de sus objetivos. De allí entonces, que las estrategias sustentantes en la interconexión de ideas y vivencias del líder, convocan a potenciar los procesos relacionados con atención, memoria, comunicación, entre otros procesos mentales de orden superior que comprometen el funcionamiento del cerebro a favor del proceso de aprendizaje, donde la emoción, la pasión u otros condicionantes, permean la generación de múltiples ideas que podrían ser más fácil, comprensiva y efectiva la gestión del rector.

\subsection{Toma de decisión y resolución de conflictos desde la capacidad atencional}

Según Braidot (2013), uno de los aspectos de la cognición humana más atractivos y de mayor aplicación para el management es la capacidad de atención, que se encuentra estrechamente relacionada con la habilidad para resolver problemas y la toma de decisiones. A continuación se presenta la figura 3 contentiva de estrategias para potenciar la capacidad atencional del líder en el contexto educativo.

Figura 3. Estrategias para la capacidad atencional.

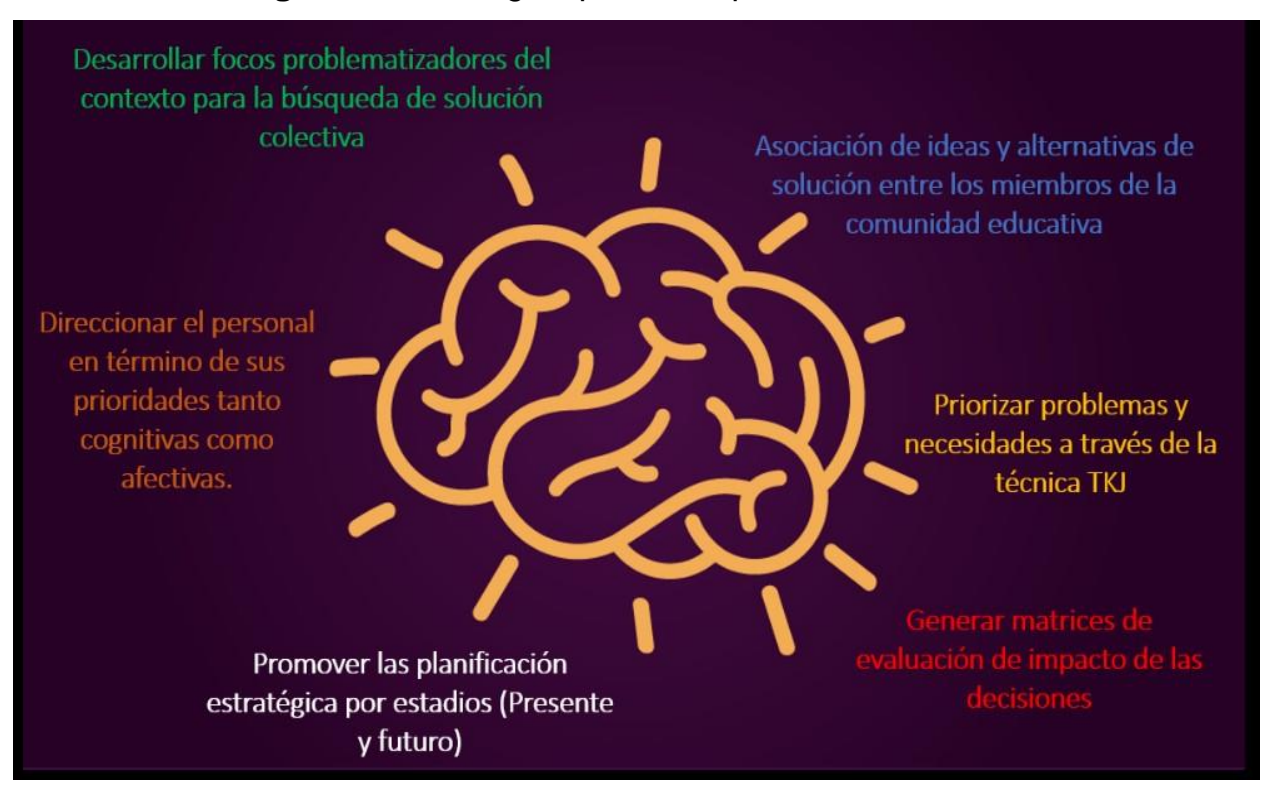

Fuente: Atencio, Ramírez y Zappa (2019) 
Las estrategias que se plantean en la figura anterior, revisten la importancia que tiene el reconocimiento e intervención de situaciones consideradas retos, desafíos o problemas en la gestión educativa, donde el líder, debe desarrollar mecanismos lógicos y organizados que le conduzcan a la toma de decisión pertinente en cuanto a las necesidades de la institución y sus objetivos, priorizando y estimando a su vez, el impacto de dicha decisión sobre la resolución de los problemas de tipo operativo, humanos, técnicos, entre otros. Es por ello, que la capacidad atencional se destina a potenciar las habilidades del líder, orientando su acción en atención a los problemas que realmente amenazan o atentan contra el logro de los objetivos educacionales.

\section{Conclusiones}

Volviendo la mirada al análisis de datos tratados conforme a cada una de las dimensiones e indicadores que conforman la variable de estudio, se concluye sobre las áreas de enfoque del neuroliderazgo, que la gestión directiva se centra en una gran proporción en la toma de decisiones, involucrando a los miembros de la comunidad educativa para la resolución de problemas y el trabajo en equipo; sin embargo, se reportó que la gestión emocional se evidencia en categoría moderada, por lo que amerita profundizar en el establecimiento de relaciones afectivas que contribuyan al logro de los objetivos organizacionales.

En cuanto al estilo de liderazgo, se concluye que la gestión del rector asume un estilo carismático y participativo que involucra, escucha, y asigna actividades a todos sus seguidores, aun cuando se presentó debilidad en el abordaje del estilo de liderazgo emocional desde la perspectiva de los docentes, lo que se corresponde con el área de gestión emocional precisada con anterioridad.

Sobre las habilidades directivas, la población objeto de estudio confirmó que la gestión del rector se efectúa sobre la base de la comunicación empática, la innovación y la planificación estratégica con total normalidad, lo que se evidencia en la tendencia general de las respuestas otorgadas. Sin embargo, el discurso y vivencia de los involucrados, apuntan a la necesidad de renovar los mecanismos y espacios bajo los cuales se propicia la acción comunicativa en el entorno institucional.

En líneas generales, se puede decir que el neuroliderazgo representa una nueva forma de sentir y vivir la gestión organizacional en instituciones de carácter educativo, donde se busca el reconocimiento, comprensión y aplicación de recursos tanto internos como externos 
del medio, que terminan condicionando la forma en que el líder conduce a la institución y sus aliados, para el logro de los objetivos que como comunidad educativa se han pautado desde la dimensión académica como administrativa. De allí entonces, que con este estudio se confirma las bondades de la neurociencias en el campo no solo educativo, sino además, en la gerencia postmoderna, la cual cree y apuesta en dinámicas organizacionales sistémicas, complejas, y ante todo, flexibles.

\section{Referencias}

Arana, Arnoldo (2012). Neuroliderazgo. Una perspectiva innovadora del liderazgo. [pdf]. Recuperado de http://www.glcconsulting.com.ve/wpcontent/uploads/2015/10/Articulo Neuroliderazgo Una Perspectiva Innovadora del Li derazgo Arnoldo Arana.pdf

Atencio, Eduardo. (2015). Gestión del conocimiento y medición del capital intelectual como recurso intangible en las organizaciones que aprenden. Análisis comparativo desde sus modelos originarios. CICAG, 13(1), 223-234. Recuperado de: https://dialnet.unirioja.es/servlet/articulo?codigo $=6932715$

Bados, Arturo y García, Eugení. (2014). Resolución de problemas. [pdf]. Recuperado de https://www.researchgate.net/publication/272815457 Bados A y Garcia Grau E 201 4 Resolucion de problemas Publicacion electronica Coleccion Objetos y Materiale s Docentes OMADO httphdlhandlenet244554764

Bazan, Roberto. (2017). La fantasía del líder y la realidad del dirigente. Revalorando a nuestros líderes y dirigentes auténticos. Sevilla, España. Pentian.

Bericat Alastuey, Eduardo. (2012). Emociones. Sociopedia.Isa, 1-13. DOI: $10.1177 / 205684601261$

Braidot, Nestor. (2013). Neuromanagement y Neuroliderazgo. Cómo se aplican los avances de las neurociencias a la conducción y gestión de organizaciones. Revista ciencias administrativas, [2]. Recuperado a partir de https://revistas.unlp.edu.ar/CADM/article/view/706

Caballero Muñoz, Domingo., y Blanco Prieto, Antonio. (2007). Competencias para la flexibilidad: la gestión emocional de las organizaciones. Revista Psicothema, 19 [4]. Recuperado de http://www.redalyc.org/pdf/727/72719412.pdf

Caballero, Leidy y Lis, Jenny. (2016). Liderazgo: una aproximación desde las neurociencias. [pdf]. Recuperado de https://dialnet.unirioja.es/descarga/articulo/6403492.pdf

Chávez, Nilda. (2009). Introducción a la investigación educativa. Maracaibo, Venezuela: Grafica González. 
Cortes, Alejandra (2004). Estilos de liderazgo y motivación laboral en el ambiente educativo. Revista de Ciencias Sociales, IV [106]. Recuperado de http://www.redalyc.org/pdf/153/15310615.pdf

Cuglievan, Gisele, y Rojas, Vanesa. (2008). La gestión escolar en el marco de la autonomía: una mirada desde el cotidiano a cinco instituciones educativas estatales de Lima. [Monografía]. http://bibliotecavirtual.clacso.org.ar/Peru/grade/20100406115943/analisis-7.pdf

Dispenza, Joel. (2007). Desarrolle su cerebro. La ciencia para cambiarla mente. Buenos Aires, Argentina: Krier.

Ferraros, Juan. (2002). Condiciones para el trabajo en equipo. [pdf]. Recuperado de http://www.ferraros.com.ar/Articulos/jif\%20condiciones\%20teeq.pdf

Ganga, Francisco. y Navarrete, Erwin. (2014). Aportaciones teóricas significativas sobre el liderazgo carismático y transformacional. Revista Venezolana de Gerencia (RVG). 19 [67]. Recuperado de: http://www.redalyc.org/pdf/290/29031856009.pdf

Goleman, David., y Boyatzis, Richard. (2008). La inteligencia social y la biología del liderazgo. Revista Harvard Business Review. 86 [9]. Recuperado de https://www.academia.edu/35508019/La inteligencia social y la biolog\%C3\%ADa de liderazgo

Mena, Milena. (2016). Neuroliderazgo: clave para la generación de la neuroplasticidad autodirigida en la gerencia. Revista de Estudios Interdisciplinarios en Ciencias Sociales Tecnología e Innovación - Renova. [1]. Recuperado de http://revistas.sena.edu.co/index.php/rnt/article/view/497

Ministerio de Educación Nacional, (2008). Guía 34, para el mejoramiento institucional de la autoevaluación al plan de mejoramiento. [Monografía]. Recuperado de https://www.mineducacion.gov.co/1759/articles-177745 archivo pdf.pdf

Pozueta, Fernando. (2015). Liderazgo Emocional. Programa para mejorar las actitudes y habilidades de liderazgo basado en las prácticas de la Inteligencia Emocional. [Monografía]. http://www.pozueta.com/documents/LIDERAZGO\%20EMOCIONAL.pdf

Rojas, Alfredo y Gaspar, Fernando. (2006). Bases del liderazgo en educación. Santiago de Chile, Chile: UNESCO.

Tamayo y Tamayo, Mario. (2008). El proceso de la investigación científica. Ciudad de México, México: Limusa.

Weinstein, José. (2002). Calidad y gestión en educación: Condiciones y desafíos. Pensamiento educativo. Revista de Investigación Educacional Latinoamericana, 31 [2]. Recuperado de http://pensamientoeducativo.uc.cl/index.php/pel/article/view/229/490 
Revista indizada en

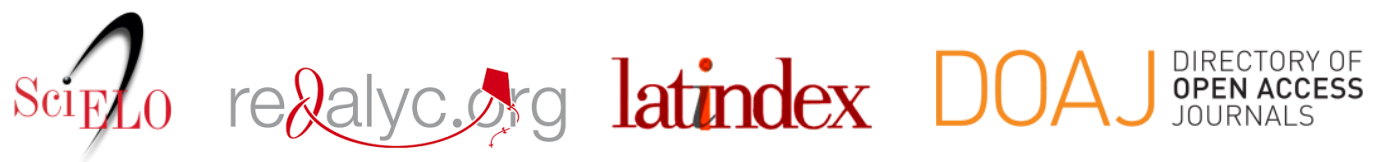

Distribuida en las bases de datos:

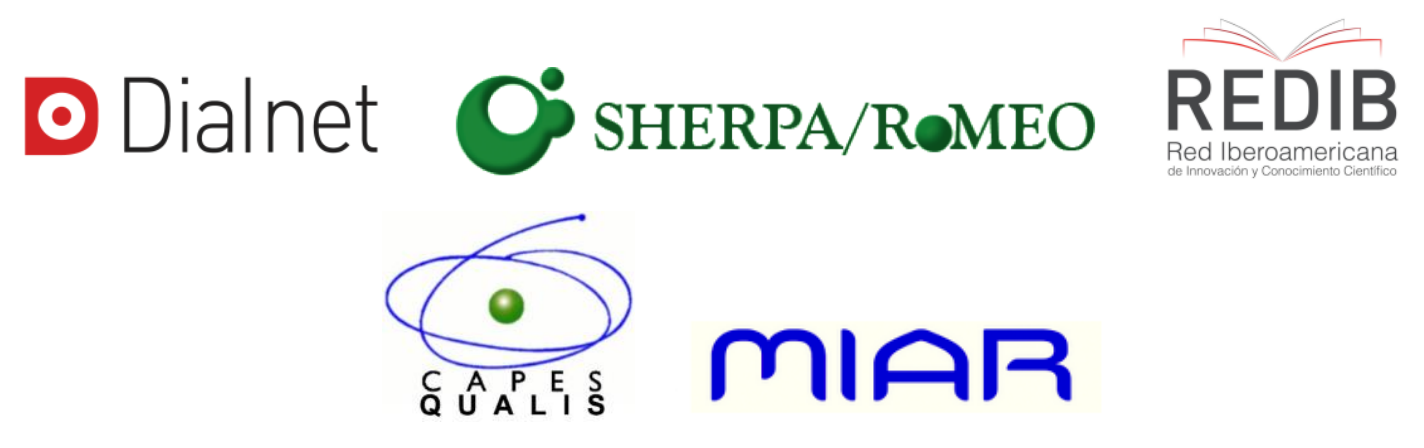

